\title{
A concurrent assessment of the positive and negative properties of a signaled shock schedule*
}

\author{
JOHN HARSH and PIETRO BADIA \\ Bowling Green State University, Bowling Green, Ohio 43403
}

\begin{abstract}
A choice and a conditioned suppression procedure were used to assess concurrently the positive and negative properties of stimuli within a signaled shock schedule. Occasional shocks were presented to Ss responding on a variable-interval food schedule. Ss could choose whether shocks occurred alone or whether they were preceded by a 1-min signal. All Ss chose the signaled shock condition over the unsignaled one, even though food reinforced responding in the presence of the signal was suppressed. Rate of responding for food varied across stimulus conditions, with the lowest rate in the presence of the signal and the highest rate in its absence. An intermediate rate occurred under the unsignaled shock schedule. A safety analysis was applied to the data.
\end{abstract}

Demonstrations of the conditioned aversive properties of preshock stimuli (signals) contrast with the findings of studies involving choice between signaled and unsignaled shocks. It has been found that signaled shock situations are preferred over unsignaled ones (Badia \& Culbertson, 1972; Badia, Culbertson, \& Lewis, 1971; Lockard, 1963; Perkins, Seymann, Levis, \& Spencer, 1966). However, data from conditioned suppression procedures (see review by Davis, 1968), conditioned punishment procedures (Hake \& Azrin, 1965), and condition fear procedures (McAllister \& McAllister, 1971) suggest that preshock stimuli in these situations acquire aversive properties.

Preference for signaled over unsignaled shock has been accounted for by assuming that signals acquire reinforcing properties. For example, it has been claimed that signals enable $S s$ to make precisely timed preparatory responses which serve to reduce the noxiousness of the oncoming event (Perkins, 1955, 1968). It has also been claimed that signals are desirable because they reduce uncertainty about the occurrence of the aversive event (Berlyne, 1960). However, neither of the latter views can deal adequately with the conditioned suppression, punishment, and fear literatures noted above. A hypothesis that can account for the latter findings and also the choice findings may be provided by further considering the differences between signaled and unsignaled situations. For example, choice for signaled conditions may be controlled by the stimulus conditions in the absence of the signal rather than by the signal itself. This view accounts for preference and at the same time allows for the acquired aversiveness of signals. Support for this notion is available (Badia \& Culbertson, 1972; Badia,

*This research was supported in part by Grant GB-33725 from the National Science Foundation. Reprints may be obtained from Pietro Badia, Department of Psychology, Bowling Green State University, Bowling Green, Ohio 43403.
Culbertson, \& Lewis, 1971; Seligman, Maier, \& Solomon, 1971).

The present study combined a conditioned suppression procedure and a choice procedure in order to provide further data concerning the factors controlling preference for signaled over unsignaled shock. Ss were first given conditioned suppression training with signal-shock pairings superimposed upon an appetitive baseline. They were next given the opportunity to change from an unsignaled to a signaled condition. Combining the two procedures provided an opportunity to evaluate the positive and negative properties of signaled schedules. Rate of responding was monitored during three stimulus conditions: (1) the presence of the signal, (2) the absence of the signal during the signaled condition, and (3) the unsignaled condition.

\section{METHOD}

\section{Subjects}

Five experimentally naive female albino rats (Holtzman Company) between 90 and 120 days old served as Ss. Each S was maintained at $80 \%$ of its free-feeding weight and fed on a $24-\mathrm{h}$ food deprivation schedule.

\section{Apparatus}

Ss were tested in an operant conditioning chamber $(36.8 \times 25.4 \times 12.7 \mathrm{~cm}$ high) located in a sound-insulated chamber. Two manipulanda were available. A lever was mounted on the front wall of the chamber $5 \mathrm{~cm}$ from one side and $7.7 \mathrm{~cm}$ above the grid floor. A trapeze bar in the shape of an inverted $T$ (constructed from $.63-\mathrm{cm}$ tubing attached to a metal strip $4.43 \times .96 \times .16 \mathrm{~cm}$ thick) was suspended from the ceiling and located $2.54 \mathrm{~cm}$ from the front edge of the lever, $1.9 \mathrm{~cm}$ from the side wall and $7.3 \mathrm{~cm}$ above the grid floor. Both manipulanda required about $20 \mathrm{~g}(0.19 \mathrm{~N})$ to depress. A Davis feeder (Model PD104) was used to dispense 45-mg food pellets into a foodcup mounted in the center of the front wall $3 \mathrm{~cm}$ above the grid floor.

A constant-current dc shock source (BRS Inc.) delivered 0.5 -sec $2-\mathrm{mA}$ shock across $.64-\mathrm{cm}$ stainless steel grid bars. The 


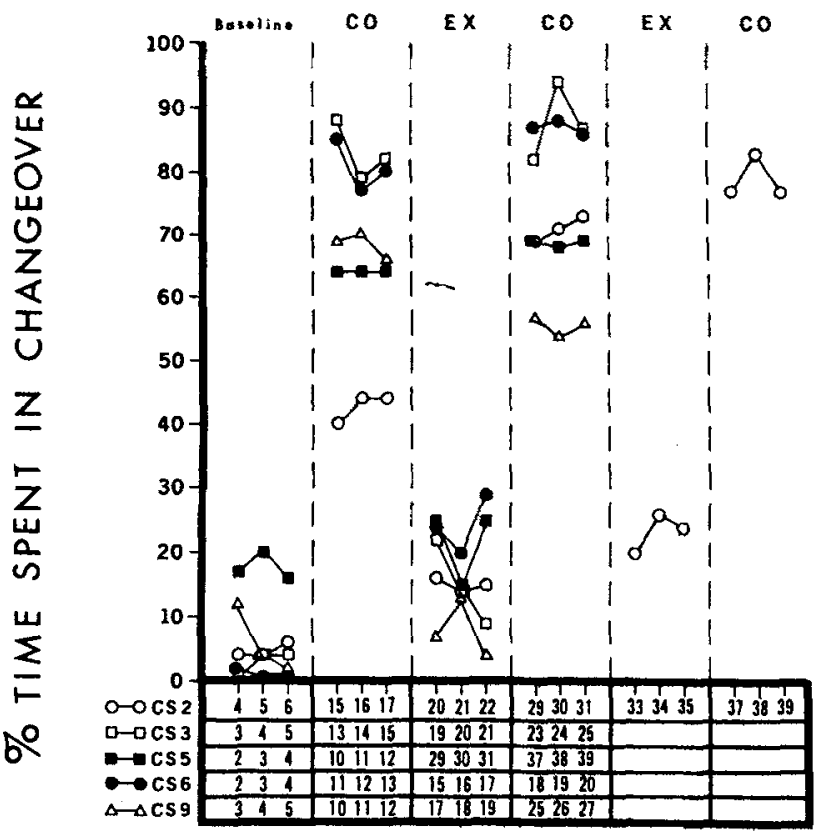

\section{SIX HOUR SESSIONS}

Fig. 1. Percent of session time spent in changeover for the last three sessions of each condition for each S (CS2, CS3, CS5, CS6, CS9). Conditions [changeover (CO) and extinction (Ex)] appear in the order in which they were administered.

grid bars were perpendicular to the width of the lever and spaced $1.90 \mathrm{~cm}$ apart, center to center. The walls and response levers served as one contact in the grid scrambling circuit. A 60 -sec tone ( $84 \mathrm{~dB}$ ) generated by a BRS oscillator (A0201) served as the preshock warning stimulus and the illumination of a $24-\mathrm{V} \mathrm{dc}$ bulb $(509 \mathrm{~K})$ covered by a $2.54-\mathrm{cm}$ white jeweled lens served as the correlated stimulus. The offset of a $24-\mathrm{V}$ dc bulb (28 ESB) covered by a $1.3-\mathrm{cm}$ white jeweled lens signaled the beginning of experimental sessions and its onset signaled the end.

\section{Procedure}

During the initial sessions, Ss were trained to barpress, and the response requirement was increased until responding was being maintained on a variable-interval schedule with a mean of $2 \mathrm{~min}$ and a range of $3 \mathrm{sec}$ to $480 \mathrm{sec}$. All VI schedules were generated with the aid of the Fleshler and Hoffman (1962) tables. Following initial training, Ss were run in 3-h sessions every other day, with the correlated stimulus on during alternate sessions.

Signal Alone Condition In order to assess the unconditioned effects of the signal on barpressing, signals withou t shocks were superimposed upon the appetitive baseline. The signals were delivered on a variable-interval $12-\mathrm{min}$ schedule (range $2 \mathrm{~min}$ to about $40 \mathrm{~min}$ ) and were $1 \mathrm{~min}$ long. The correlated stimulus was always on during this condition.

Signal Plus Shock Condition (Baseline). This condition was similar to the "signal alone condition," the major exception being that all signals were followed by shocks. Responses on the trapeze produced no stimulus changes; however, both the number of responses and the time that would have been spent in the changeover condition had these responses been effective were recorded.

Response suppression in the presence of the signal was measured by a suppression ratio $(B /(A+B)$ which contrasts rate of responding in the presence of the $1-\mathrm{m}$ in signal $(B)$ with rate of responding in the $1-\mathrm{min}$ period prior to the signal (A). Thus, a ratio of .00 represents complete response suppression in the presence of the signal, .50 represents no suppression, and points above .50 represent response facilitation.
Changeover Conditions (CO). After responding on the trapeze bar (changeove- responding) had stabilized during conditioned suppression training, Ss began the next session under the unsignaled schedule (correlated stimulus off and shock unsignaled). A response on the trapeze bar produced the signaled schedule (correlated stimulus on and all shocks preceded by signal) for $2 \mathrm{~min}$. During this period ( $\mathrm{CO}$ period), further responding on the trapeze bar produced no stimulus changes. Upon termination of the $\mathrm{CO}$ period, Ss remained under the signaled schedule unless further changeover responding occurred. Changeover responses which occurred within $2.5 \mathrm{sec}$ after a shock were ineffective. This delay was imposed because of occasional shock-elicited responding.

In order to insure an accurate calculation of the suppression ratio, $\mathrm{CO}$ periods could not terminate during the $1-\mathrm{min}$ presignal interval or during the signal. Terminations to have occurred during these intervals served only to reset timing circuitry. Further, $\mathrm{CO}$ periods could not begin during a presignal or signal interval. The changeover responses occurring during this time did produce the $\mathrm{CO}$ period; however, the timing circuits were reset to the beginning of the presignal interval.

Extinction (Ext). After changeover responding had stabilized under the $\mathrm{CO}$ condition, the changeover contingency was removed. Under this procedure, trapeze responses did not produce either the correlated stimulus or the signaled schedule.

\section{RESULTS}

\section{Changeover Responding}

A record of the percent time spent in changeover during the conditions of this experiment is shown for each $S$ in Fig. 1. Changeover responding during the various conditions was very similar to that observed in earlier studies (Badia, Culbertson, \& Lewis, 1971; Badia $\&$ Culbertson, 1972) in that all Ss changed to the signal condition when given the option. The level of responding increased when the signaled condition could be produced and decreased when it was removed. This pattern of responding is best illustrated by the data of S CS3. As can be seen in Columns 2 and 4 of Fig. 1, the time spent in the changeover condition increased to above the $80 \%$ level when responses produced the signaled condition, while time spent in changeover remained below $10 \%$ during the baseline (Column 1) and extinction (Column 3) conditions. The performances of the remaining Ss were similar but less dramatic. S CS2 received a second extinction and reacquisition session because the level of changeover performance during the second $\mathrm{CO}$ condition was higher than during the first. The third CO condition was given to determine which points represented stable responding.

\section{Conditioned Suppression}

Figure 2 depicts the suppressive effects of the signal under several conditions. As shown during the signal alone condition, the signal (tone) had a slight suppressive effect on responding prior to the signal-shock pairings. Data from the "signal plus shock" condition, however, clearly illustrate the powerful effects exerted by the signal when followed by shock. Suppression ratios at this time varied from .28 for S CS2 to as low as .05 for Ss CS3, CS5, and CS6. 
Responding in the presence of the signal continued to be suppressed when the changeover option was introduced (Points 3 and 5 of Fig. 2). Note, however, that all Ss suppressed less during the $\mathrm{CO}$ condition (Point 3) than they had prior to the CO condition. In addition, three of the five Ss suppressed less the second time the $\mathrm{CO}$ condition was presented (Point 5) than during the initial presentation. An examination of cumulative records revealed that continued exposure to the signal-shock relationship led gradually to the development of a temporal discrimination, i.e., responding during early portions of the signal increased. The gradual nature of this change is revealed by the cumulative record segments shown in Fig. 3. Figure 3A depicts the performance of S CS3 during the last day of the signal plus shock condition. As can be seen, complete suppression prevailed during most signal presentations. Figure 3B shows the distribution of responses during the last day of the initial changeover condition 10 days later for the same $\mathrm{S}$. It is clear that the $S$ was responding more during the early portions of the signals than during the later portions. A similar but less marked pattern of responding evolved for each of the remaining Ss.

The data shown in Fig. 2 (Point 4) show the effect on the suppression ratio of removing the signal. As is evident, the suppression in the interval prior to shock was eliminated. A representative pattern of responding during extinction for S CS5 is shown in Fig. 3C. Note that food reinforced responding during the condition remained at a fairly high level. The rate of reinforcement did not systematically vary during the training, changeover, and extinction conditions.

- Figure 4 provides further data concerning the relationship between food reinforced responding and the stimulus conditions prevailing during both the signaled and unsignaled conditions. Responses per minute are shown during the correlated stimulus (Condition A), during the unsignaled schedule (Condition $B$ ), and during the signal (Condition $\mathrm{C}$ ). As is clear, the rate of responding varied across stimulus conditions, with the lowest rate during the signal, an intermediate rate during the unsignaled schedule, and the highest rate during the correlated stimulus. ${ }^{1}$

\section{DISCUSSION}

The results of the present study can be summarized as follows: (1) Ss changed from an unsignaled to a signaled shock situation even though the occurrence of the signal suppressed the rate of food reinforced responding; (2) the suppressive effects of the shock schedule on the appetitive baseline varied across three stimulus conditions, with the most suppression occurring during the signal, the least occurring during the correlated stimulus, and an intermediate amount occurring during the unsignaled schedule; (3) and continued exposure to signal-shock pairings led to an increased rate of responding during the early portions of the signal.

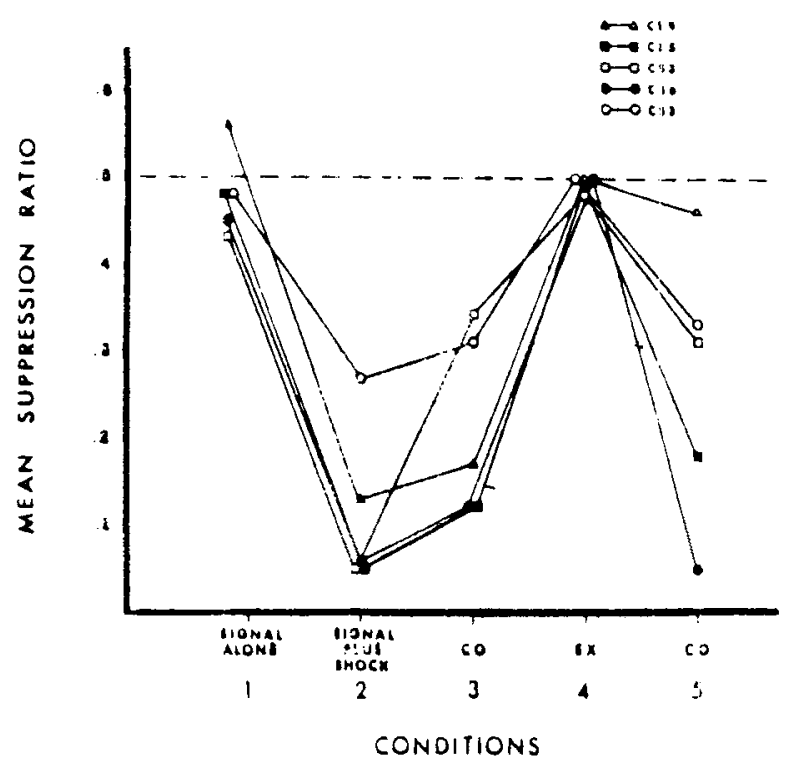

Fig. 2. Suppression ratio $(B / A+B)$ averaged over the last 3 days in each condition for each $S$.

The choice data, as well as the suppression data, are in accord with findings from previous investigations. Signaled shocks have been found to be preferred over unsignaled ones under a number of conditions (e.g., Badia \& Culbertson, 1972; Lockard, 1963; Perkins, Seymann, Levis, \& Spencer, 1966), and preshock stimuli have commonly been found to suppress the rate of ongoing food reinforced responding (see review by Davis, 1968).

The distinctive feature of the present study was the demonstration that all Ss changed from an unsignaled shock schedule to a signaled one even though presentation of the signal led to a decrease in the rate of food reinforced responding. These findings indicate that, in choice situations involving signaled and unsignaled shocks, the signaled schedule contains both positive and negative properties. More specifically, in the present experiment, the signaled condition, or some element thereof, increased the frequency of responses which produced it, i.e., it was reinforcing. The suppression data, however, indicated that at least one element of the signaled schedule (the signal) was aversive.

An analysis of the rate of food reinforced responding under three stimulus conditions (Fig. 4) supported the view that the signaled schedule relative to the unsignaled one contained both positive and negative properties. That is, food reinforced responses decreased in the presence of the signal but increased in the presence of the correlated stimulus. These findings and those of other studies support the notion that the correlated stimulus acquired positive properties, while the signal acquired negative properties.

The findings of the present study encourage an analysis of preferences which considers the behavioral control exerted by all of the stimuli which occur in the choice situation. Such an analysis has been provided by Badia et al (1971, 1972), Seligman, Maier, and Solomon 

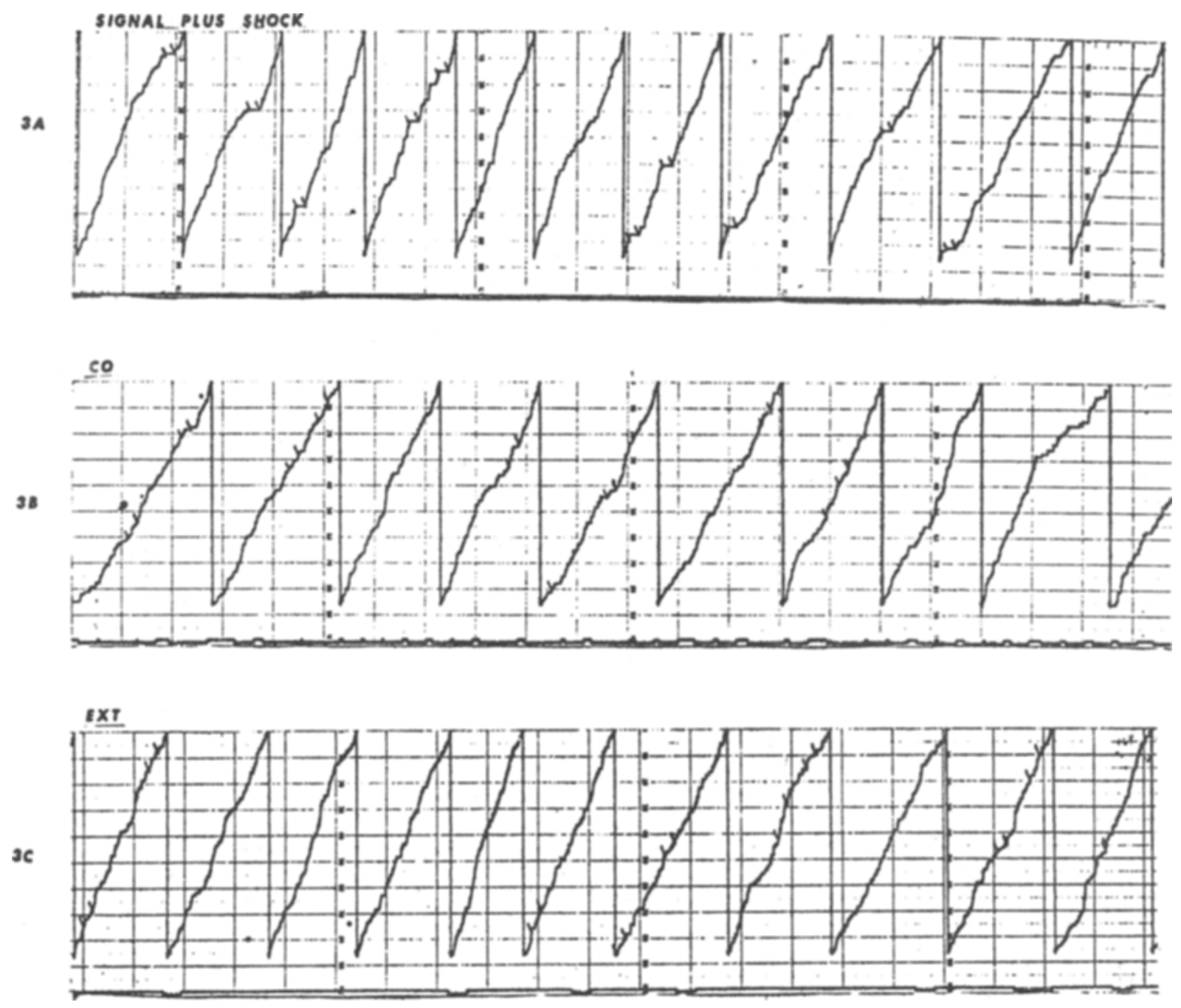

Fig. 3. Cumulative records showing the development of a temporal discrimination in the presence of the signal (3A and $3 B$ ) and the typical pattern of responding during extinction (3C).

(1971). According to Badia et al, a signaled schedule is comprised of both safe and unsafe periods. In the signal condition, the presence of the signal identifies a shock (unsafe) period, while the absence of the signal identifies a shock-free (safe) period. Under the signaled schedule, the duration of safety is as long as the intershock interval minus the signal duration. In contrast, the unsignaled condition is unsafe throughout. Therefore, changing from the unsignaled to signaled schedule may be reinforced by the safe periods of the signaled schedule.

A different account of the present findings may be provided by a preparation hypothesis. This view readily accounts for preference for signaled shock and, with the benefit of additional assumptions, can incorporate the findings presented in Fig. 4. First, it must be assumed that preparation for shock interferes with performance on a VI schedule and that a relationship exists between degree of preparation and degree of interference. Then, if it is further assumed that $\mathrm{Ss}$ in the signaled condition are most prepared in the presence of the signal, least prepared in its absence, and intermediately prepared during the unsignaled schedule, the differential rate of food responding during the three conditions (Fig. 4) is explainable. It should be pointed out that the adequacy of this account is difficult to determine, since preparatory responses may be peripheral or central (Perkins et al, 1966).

Although the preparation hypothesis can provide an account of the findings of the present study, there are two lines of evidence which argue against accepting this view as a general account of preference for predictable over unpredictable aversive events. One line of evidence involves the stimulus factors controlling choice and the second concerns the behaviorally important parameters of choice procedures.

Research designed to determine some of the stimulus factors controlling choice between schedules of aversive 


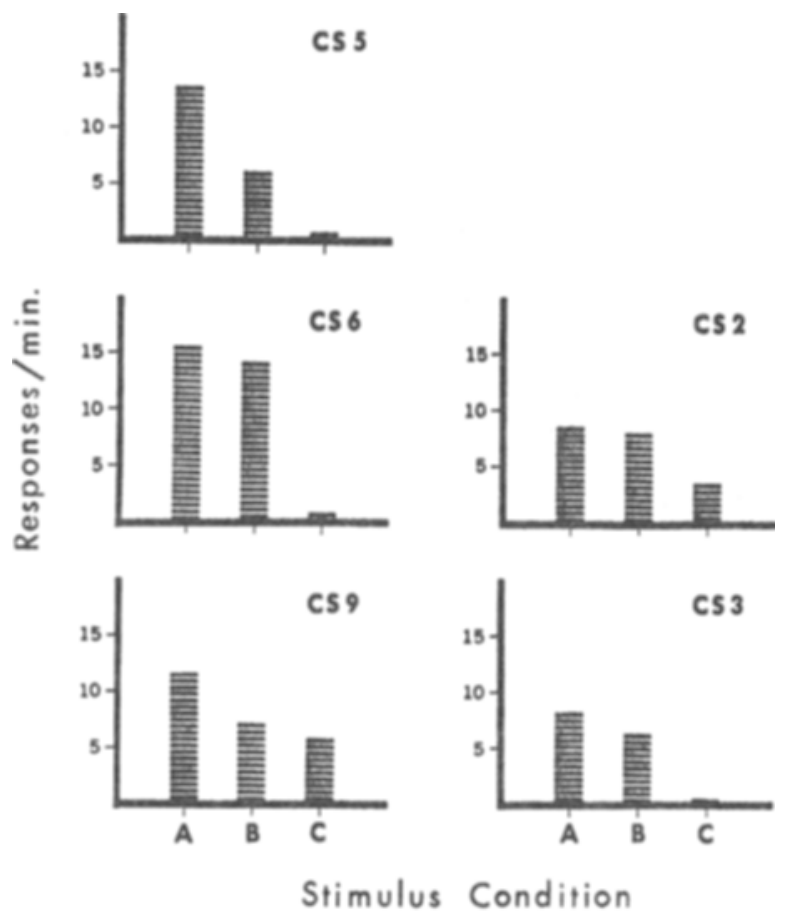

Fig. 4. Responses per minute: During the correlated stimulus (A), the unsignaled condition (B), and during the signal (C).

events have produced clear and consistent results. Badia, Culbertson, and Lewis (1971) and Badia and Culbertson (1972) have found that responses which change an unsignaled schedule to a signaled one are maintained by stimuli correlated with shock-free periods but not by stimuli (signals) correlated with shock periods. Similar findings have been obtained by Dinsmoor, Flint, Smith, and Viemeister (1969) and by Defran (1972) in their analysis of the stimuli that control observing responses. The preparation hypothesis, which is based on the behavioral importance of the signal, does not seem capable of accounting for these findings.

The preparation view also has difficulties accounting for the results of studies designed to determine the behaviorally important parameters of choice procedures. Presumably, manipulations which affect an organism's ability to reduce the aversiveness of signaled shock to levels below that of unsignaled ones should affect strength of preference. However, it has been found that Ss choose signaled shocks which are up to nine times longer, six times stronger, and two to eight times more frequent than unsignaled ones (Badia, Coker, \& Harsh, 1973; Badia, Culbertson, \& Harsh, 1973). It does not seem possible that preparatory responses under these conditions could have reduced the aversiveness of signaled shocks to levels lower than unsignaled ones.

Much of the data used to argue against accepting a preparation hypothesis can also be used against an information-seeking approach. The findings, however, are compatible with-indeed, serve as-an empirical foundation for a safety analysis.

\section{REFERENCES}

Badia, P., \& Culbertson, $S$. The relative aversiveness of signaled vs unsignaled escapable and inescapable shock. Journal of the Experimental Analy sis of Behavior, 1972, 17, 463-471.

Badia, P., Culbertson, S., \& Lewis, P. The relative aversiveness of signaled vs unsignaled avoidance. Journal of the Experimental Analysis of Behavior, $1971,16,113-131$.

Badia, P., Coker, C., \& Harsh, J. Choice of higher density signaled shock over lower density unsignaled shock. Journal of the Experimental Analysis of Behavior, 1973, 20, 47-55.

Badia, P., Culbertson, S., \& Harsh, J. Choice of longer or stronger signaled shock over shorter or weaker unsignaled shock. Journal of the Experimental Analysis of Behavior, $1973,19,25-32$.

Berlyne, D. E. Conflict, arousal, and curiosity. New York: MeGraw-Hill, 1960.

Davis, H. Conditioned suppression: A survey of the literature. Psychonomic Monograph Supplements, 1968, 2(Whole No. 30), 283-291.

Defran. R. H. Reinforcing effects of stimuli correlated with schedules of aversive stimulation. Unpublished doctoral dissertation, Bowling Green State University, Bowling Green, Ohio, 1972.

Dinsmoor, J. A., Flint, G. A., Smith, R. F., \& Viem eister, N. F. Differential reinforcing effects of stimuli associated with the presence or absence of a schedule of punishment. In D. P. Hendry (Ed,), Conditioned reinforcement. Homewood, lll: Dorsey, 1969. Pp. 357-384.

Fleshler, M., \& Hoffman, H. S. A progression for generating variable-interval schedules. Journal of the Experimental Analy sis of Behavior, $1962,5,529-530$.

Hake, D. F., \& Azrin, N. H. Conditioned punishment. Journal of the Experimental Analysis of Behavior, 1965, 8, 279-293.

Hendry, D. P. Reinforcing value of information: Fixed ratio schedules. In D. P. Hendry (Ed.), Conditioned reinforcement. Homewood, Il: Dorsey, 1969. Pp. 300-342.

Knapp, R. K., Kause, R. H., \& Pexkins, C. C., Jr. Immediate vs delayed shock in $T$ maze performance. Journal of Experimental Psychology, 1959, 58, 357-362.

Lockard, Joan S. Choice of warning signal or no warning signal in an unavoidable shock situation. Journal of Comparative \& Physiological Psychology, 1963, 56, 526-530.

McAllister, W. R., \& McAllister, D. E. Behavioral measurement of conditioned fear. In F. R. Brush (Ed.), Aversive conditioning and learning. New York: Academic Press, 1971. Pp. 105-179.

Perkins, C. C., Jr. The stimulus conditions which follow learned responses. Psychological $R$ eview, 1955, 62, 341-348.

Perkins, C. C., Jr. An analysis of the concept of reinforcement. Psychological R eview, 1968, 75, 155-172.

Perkins, C. C., Jr., Seymann, R. G., Levis, C. J., \& Spencer, H. R., Jr. Factors affecting preference for signal-shock over shock-signal. Journal of Experimental Psychology, 1966, 72, 190-196.

Seligman, M. E. P., Maier, S. F., \& Solomon, R. L. Unpredictable and uncontrollable aversive events. In F. R. Brush (Ed.), Aversive conditioning and learning. New York: Academic Press, 1971. Pp. 347-400.

\section{NOTE}

1. Findings similar to those reported here were obtained in our laboratory with tail electrodes in an unpublished study by Preston Harley.

(Received for publication January 22, 1974; revision received April 17, 1974.) 